Research Article

\title{
Systematic Performance Evaluation of Shield TBM Cutters for Excavating Multiple Soft Rock
}

\author{
Chuyuan Cao $\mathbb{D D}^{1}$ and Kui Zhang $\mathbb{D}^{1,2}$ \\ ${ }^{1}$ Engineering Research Center of Complex Tracks Processing Technology and Equipment of Ministry of Education Xiangtan, \\ Xiangtan University, Xiangtan 411105, China \\ ${ }^{2}$ College of Mechanical Engineering, Xiangtan University, Xiangtan 411105, China
}

Correspondence should be addressed to Kui Zhang; zhangk@xtu.edu.cn

Received 12 May 2021; Accepted 11 June 2021; Published 21 June 2021

Academic Editor: Jie Liu

Copyright (C) 2021 Chuyuan Cao and Kui Zhang. This is an open access article distributed under the Creative Commons Attribution License, which permits unrestricted use, distribution, and reproduction in any medium, provided the original work is properly cited.

\begin{abstract}
Cutter performance evaluation is important for shield TBM during the design and refurbishment stage. To face the challenges of choosing the proper cutters for tunneling in complex condition, according to the concept of parameter profile analysis, a systematic evaluation method was proposed. In this novel method, by comparing with their expected best value and the corresponding unacceptable limit, all of the selected performance parameters can be synthesized to assess the proximity of the overall merit of each cutter with respect to all the performances considered under all possible geological conditions. Performance indexes including cutting efficiency, structural strength, wear life, and dynamic response were individually analyzed based on linear cutting tests, finite element analyses, and theoretical calculations. Finally, a case study was carried out to demonstrate how the method is applied to find the optimal cutter among a small-scale disc cutter and two scrapers used for cutting multiple soft rock. In this case, three types of concrete specimens with distinct mechanical properties were carefully prepared to substitute for soft rock. The evaluation results show that the method has an intrinsic applicability in helping to make a reasonable trade-off between cost and cutting performance during the cutter selection process.
\end{abstract}

\section{Introduction}

Shield tunnel boring machine (TBM) is an advanced tunneling device, commonly employing scrapers and disc cutters to excavate soft rock and soil encountered [1]. As a basic functional unit of the cutterhead, the cutters are installed on a cutterhead using a certain layout and their merit is determined by mechanical and geological parameters (e.g., rock hardness, strength, and abrasiveness) [2,3]. So it seems that cutter design is an interesting geomechanical synthesis exercise involving a multifactor evaluation.

Currently, most researchers focus on the study of cutting forces and their associated performances such as specific spacing/penetration corresponding to the minimum specific energy based on cutting tests $[4,5]$. These analyses provide some insights into performance evaluation of TBM cutters [6]. However, since only a few performance parameters and a limited range of geological conditions are taken into account, some well-designed cutters which perform well under a certain tunneling ground may not satisfy the multiple requirements of some complex environments which contain different or even diametrically opposite geological conditions. There seems to be a lack of an efficient way to provide a systematic evaluation of multiple performances of TBM cutters under different geological conditions [7].

In this context, a novel evaluation method is proposed, which considers a comprehensive list of individual performances at varying geological grounds. To illustrate how the evaluation method is applied to find the optimal cutter, a case study was then given. In this case, the cutting performance of a small-scale disc cutter and two scrapers which were originally designed for excavating soft rock was analyzed and evaluated individually based on linear cutting tests, finite element analyses, and theoretical calculations; 
three types of concrete specimens with distinct mechanical properties were carefully prepared to substitute for soft rock. Finally, all the performance indexes of the cutters were then systematically analyzed and the overall merits of the cutter design were discussed.

\section{Performance Evaluation Principles}

2.1. Performance Parameters. Based on linear cutting tests and finite element analyses (FEA), the following performance parameters can be obtained.

2.1.1. Specific Energy (SE). It is a widely used index for assessing the cutting efficiency of TBM cutters. Unexpected high SE not only suggests that the cutting process is inefficient, but also implies that potential failures such as excessive wear happen [8]. Considering that the rock-breaking process in the rolling direction consumes almost all of the cutting energy, the energy expended in the vertical direction is comparatively negligible [9]. Therefore, SE is then calculated as follows:

$$
\mathrm{SE}=\frac{F_{h} \times l_{x}}{m_{r} / \rho_{r}},
$$

where SE is expressed in $\mathrm{MJ} / \mathrm{m}^{3} ; F_{h}$ is the mean value of horizontal cutting force or rolling force measured by the strain gauges as shown in Figure $1, \mathrm{kN} ; \rho_{r}$ is the rock density, $\mathrm{kg} / \mathrm{mm}^{3} ; m_{r}$ is the mass of rock debris, $\mathrm{kg}$; and $l_{x}$ is the horizontal cutting displacement of TBM cutters, $\mathrm{m}$.

2.1.2. Cutting Coefficient (CC). The ratio of the horizontal force to the vertical force is expressed as a percentage which can be considered as an indicator of the amount of torque needed for a given amount of thrust; the higher the CC, the higher the torque needed by TBMs [3].

2.1.3. Magnitude of Cutting Vibration. Due to the characteristics of rock and discontinuities, the cutting vibration is a ubiquitous problem, resulting in seal failures, fatigue cracks on cutter tips, and bolt looseness [10]. The magnitude of vibration acceleration reflects the intensity of the external excitation and therefore represents the dynamic performance. In this paper, only vertical vibration acceleration $a_{v}$ is considered.

2.1.4. Maximum Equivalent Stress, $\sigma_{\max }$. Structural strength of TBM cutters is another criterion to check whether the cutters can withstand heavy cutting load and to examine whether the stress concentration occurs on the cutter tips. It is hard to directly obtain the stress distribution of the cutters by theoretical calculation. Considering that FEA is widely used in engineering analysis and calculation, we use the finite element analysis software ANSYS to calculate the maximum equivalent stress $\sigma_{\max }$. Before solving the static FE model in ANSYS, the experimental mean cutting forces are applied on the contact surface of the cutter ring with rock in the form of nodal forces. Meanwhile, uniform radial nodal displacement $\delta_{\min }$ is applied on the nodes attached to the inner surface of the cutter ring to simulate the interference fit. $\delta_{\min }$ is set to $0.05 \mathrm{~mm}$.

2.1.5. Wear Life, $l_{w}$. Cutter wear incurs the costs of downtime as well as the costs of refurbishing and replacing the cutters [11]. Therefore, it is a critical factor contributing to performance. Based on site surveys, Wijk proposed that the wear life should be approximately inversely proportional to $\mathrm{CAI}^{2}$ and $\left(\sigma_{c} \sigma_{c}\right)^{1 / 2}$ and proportional to the wear volume of the cutters $V_{x}$ and the cutting pressure on rock $F_{v} / w$ [12]. Incorporating all the assumptions above, the wear life $l_{w}$ can be calculated by

$$
l_{w}=\frac{\sum V_{w} w_{\max }}{\left[F_{v} \sqrt{\sigma_{c} \sigma_{t}}(\mathrm{CAI})^{2}\right]},
$$

where $w_{\max }$ is the maximum allowable tip width of a worn cutter, $m ; V_{w}$ can be easily calculated according to the geometric characteristics of cross-sections of the worn cutter with a given $w, \mathrm{~m}^{3}$; wear coefficient $\Sigma$ is set to $2.024 \times 10^{24} \mathrm{~Pa}^{2} / \mathrm{m}$; CAI is Cerchar abrasivity indices; $\sigma_{c}$ is uniaxial compressive strength, $\mathrm{Pa}$; and $\sigma_{t}$ is tensile strength, $\mathrm{Pa}$.

2.2. Evaluation Method. Multiple performance parameters and geological conditions would make the evaluation more realistic but also would greatly complicate the evaluation process. To tackle this problem, a systematic evaluation method is proposed based on the concept of parameter profile analysis [13]. A $m \times n$ performance data matrix (PDM) $\left(d_{i j}\right)$ can be obtained which is a schematic representation of a collection of performance parameters $P_{i}(i=1$, $2, \ldots, m)$ for multiple specimen $S_{j}(j=1,2, \ldots, n)$. PDM can be further converted into the matrix $\mathrm{PDM}^{\prime}$ in which all data points have upper acceptable limits. For example, if $P_{m}$ has a lower acceptable limit, the inverse of the data point must have the upper acceptable limits.

The system should be best considered with respect to the limits of performances that may be acceptable, and the best performances that can be expected from the TBM applications. Therefore, upper boundary matrix (UBM) $\left(u_{i j}\right)_{m \times n}$ and margin rate matrix (MRM) $\left(m_{i j}\right)_{m \times n}$ are defined here to represent the upper acceptable limit and the expected best improvement rate of $i$-th parameter under $j$-th geological condition, respectively. Both of the matrices can be determined from technical literatures or from the estimations by experienced designers. The character of the system can be assessed by a review of the profile of the performance parameters at different geological conditions with respect to the proximity of actual performances to the unacceptable limits and the best values of the performances. The parameter profile matrix (PPM) is then introduced as follows: 


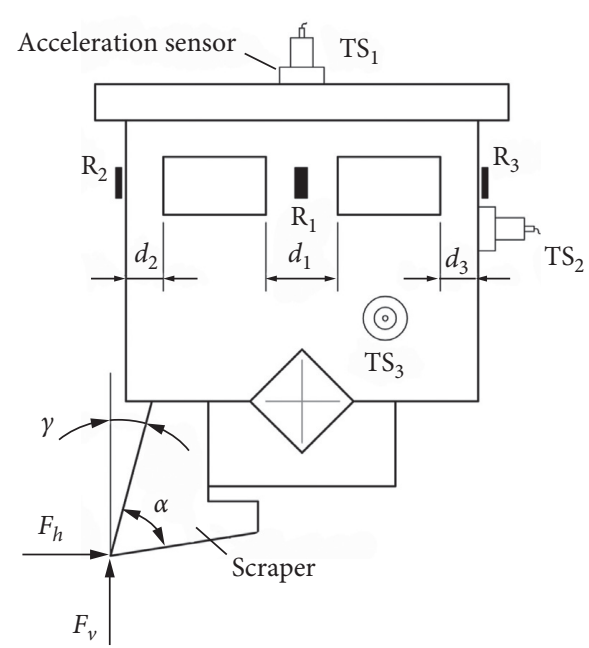

(a)

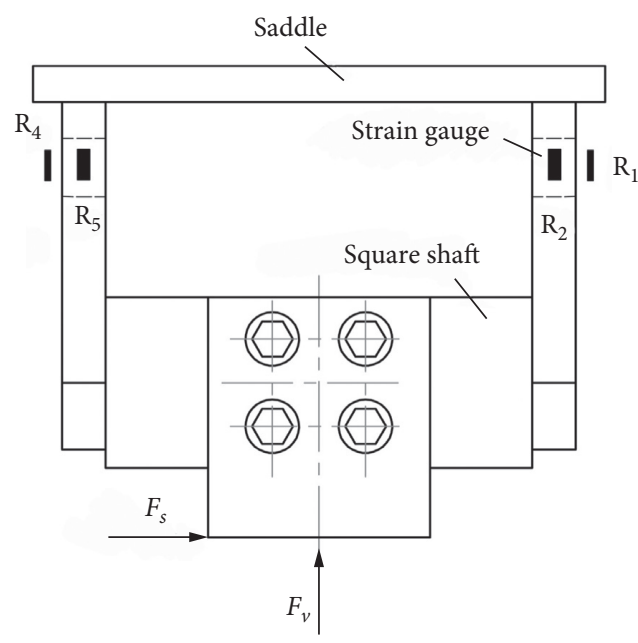

(b)

FIGURE 1: Illustration of sensors attached on the saddle.

$$
\mathrm{PPM}=\left(\frac{\mathrm{UBM}-\mathrm{PDM} A}{\mathrm{UBM} \times \mathrm{MRM}}\right) \times 10 .
$$

To ensure that the data point in the PPM $\left(D_{i j}\right)$ is a nondimensional number within the range $0-10$, if $D_{i j}>10$, it is set at 10 ; if $D_{i j}<0$, it is set at 0 . For each row and column (i.e., for each parameter and geological condition), the mean and standard deviation (SD) are calculated. The SD is a measure of the degree of the dispersion of the data around the mean. A cutter with satisfactory performance should have a low SD and a high mean. The existence of high SD signifies that the cutters will be likely to have significant problematic areas; a high SD for a row indicates a variable performance under different geological conditions in the design for a particular parameter; a high SD for a column indicates that the cutters will have significant problematic performance under that geological condition.

To analyze the performance at a more advanced level, a parameter performance index $\mathrm{PPI}_{i}$ and a case performance index $\mathrm{CPI}_{j}$ can be defined as

$$
\begin{aligned}
\mathrm{PPI}_{i} & =\frac{n}{\sum_{j=1}^{n}\left(2 / D_{i j}\right)}, \quad(i=1,2, \ldots, m), \\
\mathrm{CPI}_{j} & =\frac{m}{\sum_{i=1}^{m}\left(1 / D_{i j}\right)}, \quad(j=1,2, \ldots, n) .
\end{aligned}
$$

From equations (4) and (5), the indices are calculated by summing the inverse of the data points to attenuate the effect of any particularly low scores being hidden by high scores in other respects, and this is possible when only the mean is calculated. The system may be reviewed as follows:

(1) A comparison of PPIs will indicate whether the system performs better with respect to some performances than others
(2) A comparison of CPIs will show whether the system performs significantly better at some geological conditions than others

The mean values, CPIs, PPIs, and SDs provide an efficient way to analyze the system from different perspectives. An overall performance index (OPI) is then used to develop the overall objective function. The OPI, which takes the form of a qualitative score, can be established for the system by considering all the performances and all the geological conditions. The OPI function lies in the range of 0-100. Each performance parameter and each geological condition are given a weighting value according to its importance. The OPI can be expressed as follows:

$$
\mathrm{OPI}=\sum_{i=1}^{m} \sum_{j=1}^{n}\left(w_{P_{i}} \cdot \mathrm{PPI}_{i}\right) \times\left(w_{S_{j}} \cdot \mathrm{CPI}_{j}\right),
$$

where $W_{P i}$ and $W c_{j}$ are weighting factors in the range of $0-1$ reflecting the preference for different parameters and different geological conditions. Weighting factors satisfy the following equations:

$$
\left\{\begin{array}{l}
\sum_{i=1}^{m} w_{P_{i}}=1, \\
\sum_{j=1}^{n} w_{S_{j}}=1 .
\end{array}\right.
$$

\section{Case Study}

3.1. Experimental Platform and Cutters. The cutting tests were performed on the standard linear cutting machine (LCM) with the size of $3.7 \mathrm{~m} \times 1.7 \mathrm{~m} \times 3 \mathrm{~m}$ (see Figure 2(a)) at the State Key Laboratory of High Performance Complex Manufacturing of Central South University. The system is designed for cutter loads up to $440 \mathrm{kN}$ (vertical) and $220 \mathrm{kN}$ 


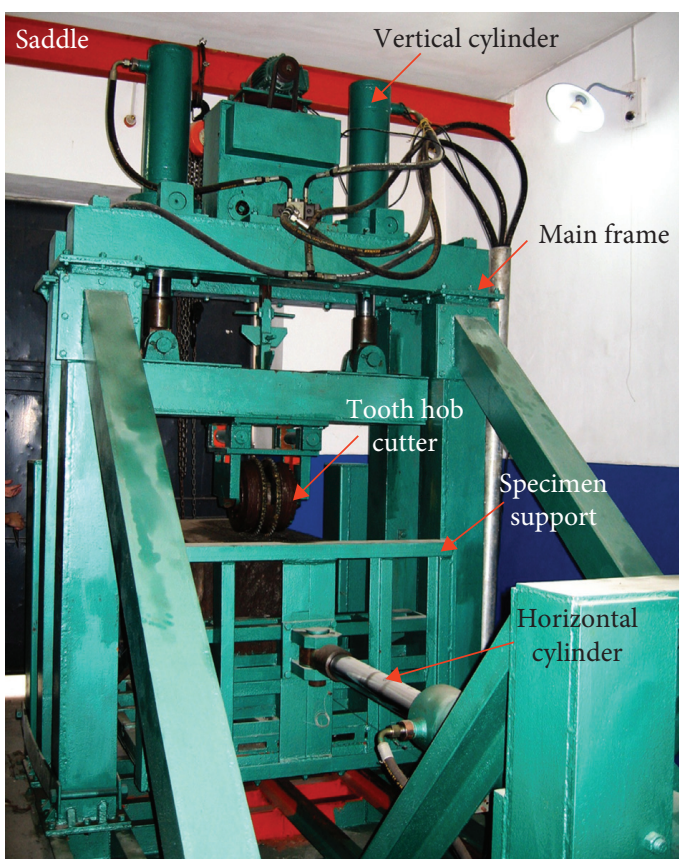

(a)

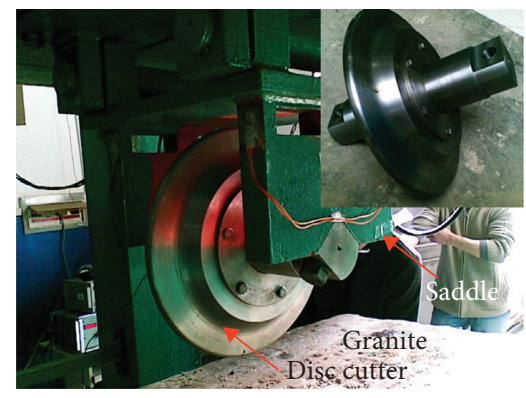

(b)

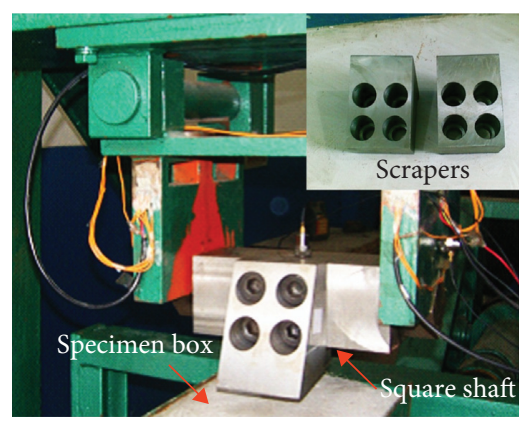

(c)

Figure 2: (a) main frame of LCM; (b) disc cutter; (c) two scrapers.

(horizontal) with sufficient stiffness to minimize the rig deflections during the tests. A disc cutter (Figure 2(b), numbered as C1) and two scrapers (Figure 2(c), numbered as $\mathrm{C} 1$ and $\mathrm{C} 2$ ) were used in cutting tests. $\mathrm{C}_{1}$ is an $8.5^{\prime \prime}$ constant-cross-section disc cutter with $6.5 \mathrm{~mm}$ tip width. $\mathrm{C}_{2}$ and $\mathrm{C}_{3}$ have the same tip width $120 \mathrm{~mm}$ with different rake angles $\gamma 10^{\circ} / 20^{\circ}$ and edge angles $\alpha 70^{\circ} / 60^{\circ}$. To reduce costs, the above cutters were made of standard hardened steel.

As the LCM was originally designed for cutting granite by roller cutters such as disc cutters and spherical tooth hob cutters [14], a special square shaft (see Figure 1) was specifically designed to fix $\mathrm{C}_{2}$ and $\mathrm{C}_{3}$ on the saddle by screw blots. As shown in Figure 1, strain gauges were attached on the saddle in certain pattern, ensuring that the cutting forces were measured in three directions precisely (vertical, horizontal or rolling, and side). Vibration signals were also measured by acceleration sensors.
3.2. Specimen Preparation. It is hard to control rockbreaking tests due to the randomness of natural rocks. To overcome this shortcoming, concrete specimens were used to substitute for soft rock in this paper. By strictly controlling concrete curing time and the ratios of fine sand $(0-4 \mathrm{~mm})$, cobblestones, commercial cement, and water, three sets of concrete specimens with distinct mechanical properties (referred to as $S_{1}, S_{2}$, and $S_{3}$ ) were separately casted in specimen boxes. During cutting tests, each box can be firmly fixed on the granite base.

Rock samples' mechanical properties were tested on WHY-200 automatic compression testing machine. CAIs were measured according to Cerchar method ASTM D762510 [15]. The average properties and component ratios are listed in Table 1. The ratio of compressive to tensile strength in $S_{1}$ is close to 23 , indicating an anticipated brittle behavior. On the contrary, a typical elastic-plastic behavior would be 
TABLE 1: Mechanical properties and component ratios of the specimens.

\begin{tabular}{lccccccc}
\hline No. & Elastic module, $\mathrm{MPa}$ & $\sigma_{c}, \mathrm{MPa}$ & $\sigma_{t}, \mathrm{MPa}$ & $\mathrm{CAI}$ & Component ratios $^{\mathrm{a}}$ & Cure time (weeks) $^{\text {Moisture content (\%) }}$ \\
\hline $\mathrm{S}_{1}$ & 1880 & 31.82 & 1.39 & 2.4 & $15 \%-0-85 \%$ & 3 & 3.5 \\
$\mathrm{~S}_{2}$ & 898.6 & 19.14 & 2.55 & 4.0 & $35 \%-0-65 \%$ & 2 & 8 \\
$\mathrm{~S}_{3}$ & 683.58 & 10.59 & 1.29 & 3.5 & $20 \%-25 \%-55 \%$ & 1 & 17 \\
\hline
\end{tabular}

${ }^{a}$ In sand-cobblestone-cement order.

observed in $S_{3}$. It also can be seen that $S_{2}$ with an abundance of quartz-rich sand is expected to be more abrasive, which will intensively decrease the wear life of the cutters [16]. It is worth to note that the sizes of the concrete specimens are large enough (nominally $1072 \times 250 \times 144 \mathrm{~mm}$ ) compared with the sizes of the cutters.

3.3. Experimental Scheme. During the tests, the hydraulic system moves three cylinder rams: the two vertical rams force the cutters to penetrate the specimen surface to depths of $8 \mathrm{~mm}$ while the other one moves the specimen box horizontally to cut the specimen. The moving direction of the support is away from the viewer (Figure 2(a)). Each cutter has to cut three specimens, respectively. To ensure that each cut is made without the influence of the previous cut, the specimens are only allowed to be used once. During the experiment, the cutting length was kept the same and the cutting force of the hob was recorded in real-time.

\section{Results and Discussion}

4.1. Performance Analysis. Set $\mathrm{P}=\left[\mathrm{SE}, \mathrm{CC}, a_{v}, \sigma_{\max }, l_{w}\right]$ and $\mathrm{S}=\left[\mathrm{S}_{1}, \mathrm{~S}_{2}, \mathrm{~S}_{3}\right]$. All the performance results at all the geological conditions in Table 2 are obtained individually and analytically. These data are ready for processing using the proposed evaluation method. Tests also support the above notions. $\mathrm{C}_{1}$ produced more fragmentations in $\mathrm{S}_{1}$ (Figure 3(a)) than in $S_{3}$. Furthermore, when the penetration depth continues to increase, $S_{3}$ is fully compressed due to elastic-plastic deformation (Figure 3(c)) and the volume of debits increases slightly. As shown in Figures 3(d) and 3(e), scrapers can fragment soft rock more efficiently.

In Table 2, the maximum stresses $\sigma_{\max }$ of $\mathrm{C}_{2}\left(\mathrm{C}_{3}\right)$ are overwhelmingly larger than those of $\mathrm{C}_{1}$ when cutting the same specimen. The simplest explanation is that stress concentrations occur around the sharp tips of $\mathrm{C}_{2}\left(\mathrm{C}_{3}\right)$. Another limitation of the sharp tips is their short wear life $(1.99 \mathrm{~km})$ which is only approximately one fourth as much as the shortest wear life of $C_{1}(7.21 \mathrm{~km})$.

The vibration data can help gain a better understanding of the underlying mechanisms with respect to dynamic performance. Frequency-domain analysis shows that TBM cutters are vibrating at low frequency. Vertical vibration amplitude of $C_{1}$ is appreciably larger in $S_{1}$ than that in $S_{2}$ and $\mathrm{S}_{3}$, which suggests that UCS contributes more to vibrational components than the discontinuities. On the contrast, intense vibration can be found when $\mathrm{C}_{2}\left(\mathrm{C}_{3}\right)$ cut cobblestonerich specimen $S_{2}$. This may be explained by the fact that $C_{2}$ $\left(\mathrm{C}_{3}\right)$ has higher odds of crashing against these hard cores than $\mathrm{C}_{1}$ due to the larger contact area.
4.2. Systematic Evaluation. The UBM and MRM are listed in Table 3. The PPM can now be drawn up in Table 4.

The nondimensional data in PPM represents the proximity of the calculated performance to the limits of performance. As shown in Table 4, $\mathrm{C}_{1}$ is found to have the lowest rating (1.32) with respect to $\mathrm{SE}$ when cutting $\mathrm{S}_{3}$, followed by 1.44 with respect to $\mathrm{CC}$ when cutting the same specimen. As discussed before, $\mathrm{C}_{1}$ performs poorly in respect of cutting efficiency while in some other respects, $\mathrm{C}_{1}$ performs well. For example, there are no concerns on the stress level in the structure which is the most conservative aspect of the design (marked 10). Therefore, it is still hard to find the weakest spots in design.

To reveal the character of the cutters more clearly, the means, SDs, and PPIs are listed in Table 5. It can be seen that the maximum stress $\sigma_{\text {max }}$, and $a_{v}$ of $C_{1}$ have high means and low SD; correspondingly, the PPIs for these parameters are high. This means that the design is uniformly good for all specimens with respect to structural strength and dynamic response. However, PPIs of SE and CC are clearly lower than the other performance parameters, which suggests that $C_{1}$ should be the weakest in these respects. In addition, the corresponding means are low, coupled with relative high SDs, which indicates a variable performance across the three specimens. Similarly, $\mathrm{C}_{2}\left(\mathrm{C}_{3}\right)$ is designed to be uniformly good for all specimens with respect to $a_{v}$, but the weakest spots are the structural strength and wear life.

Profile analysis of PPM is conducted for each row. Similarly, inspection of Table 6 can reveal the toughest geological condition for each cutter quantitatively. As shown in Table $6, \mathrm{C}_{1}$ performs much better in $\mathrm{S}_{1}$ than in other specimens while the opposite is found for $\mathrm{C}_{2}\left(\mathrm{C}_{3}\right)$.

As discussed above, an overall analysis across all specimens and across all performance parameters is conducted separately, which enables the designers to quickly find the weakest performance spot and toughest geological condition. It is a powerful tool in product trial and cutter refurbishment to improve the weak spots. For example, according to the above analysis, $\mathrm{C}_{1}$ can be redesigned as a double-edge cutter which is made from the same steel used in the original cutter due to the sufficient structural strength. As the cutting spacing between two edges may induce their lateral cracks to interact, a significant improvement in SE can be expected [3]. Another benefit of the design is that the proposed design will produce more friction and therefore reduce CC owing to its double contact area with the specimens. Similarly, to increase strength and durability, $\mathrm{C}_{2}$ $\left(C_{3}\right)$ can be further divided into two parts: a body base and an embedded knife blade. As the blade is made of highquality alloy steel, a significant improvement in $\sigma_{\max }$ and $l_{w}$ can be expected. In practice, trade-off between cost and 
TABle 2: Performance data $\left(g=9.8 \mathrm{~m} / \mathrm{s}^{2}\right)$.

\begin{tabular}{lccccccccc}
\hline & $\mathrm{C}_{1}-\mathrm{S}_{1}$ & $\mathrm{C}_{1}-\mathrm{S}_{2}$ & $\mathrm{C}_{1}-\mathrm{S}_{3}$ & $\mathrm{C}_{2}-\mathrm{S}_{1}$ & $\mathrm{C}_{2}-\mathrm{S}_{2}$ & $\mathrm{C}_{2}-\mathrm{S}_{3}$ & $\mathrm{C}_{3}-\mathrm{S}_{1}$ & $\mathrm{C}_{3}-\mathrm{S}_{2}$ & $\mathrm{C}_{3}-\mathrm{S}_{3}$ \\
\hline $\mathrm{SE},\left(\mathrm{MJ} / \mathrm{m}^{3}\right)$ & 12.52 & 15.84 & 18.28 & 9.02 & 6.32 & 4.85 & 8.28 & 6.93 & 4.40 \\
$\mathrm{CC}(\%)$ & 15.6 & 16.1 & 18.7 & 36.4 & 33.5 & 32.6 & 32.0 & 31.7 & 29.1 \\
$a_{v},(\mathrm{~g})$ & 0.44 & 0.39 & 0.32 & 0.46 & 0.38 & 0.53 & 0.38 & 0.32 & 0.46 \\
$\sigma_{\max },(\mathrm{MPa})$ & 33.91 & 9.77 & 6.82 & 270.64 & 158.93 & 64.80 & 278.99 & 165.08 & 67.14 \\
$l_{w},(\mathrm{~km})$ & 7.21 & 8.60 & 30.63 & 3.68 & 2.13 & 12.85 & 3.43 & 1.99 & 12.0 \\
\hline
\end{tabular}

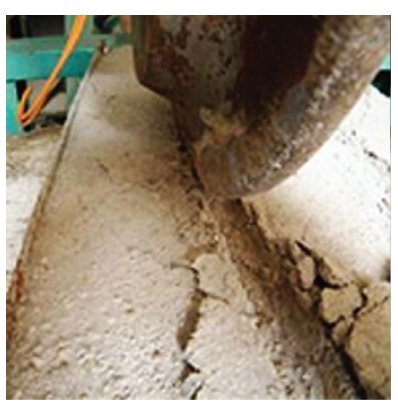

(a)

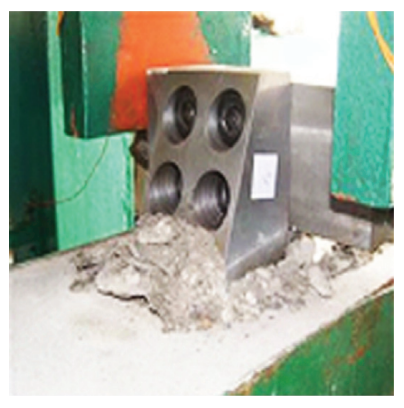

(d)

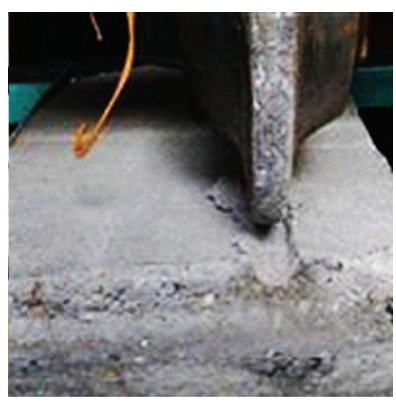

(b)

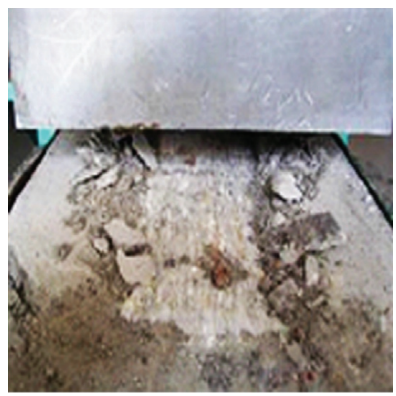

(e)

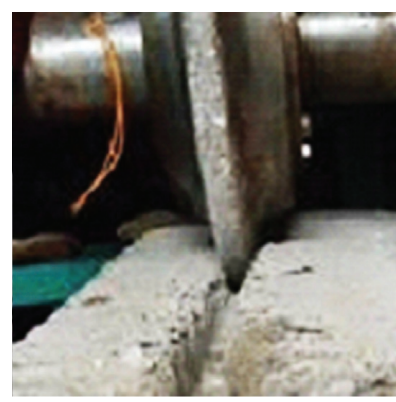

(c)

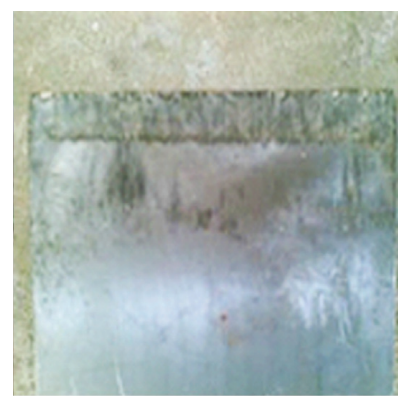

(f)

Figure 3: Rock-breaking phenomena captured in the tests. (a) $C_{1}-S_{1}$. (b) $C_{1}-S_{2}$. (c) $C_{1}-S_{3}$. (d) $C_{3}-S_{1}$. (e) $C_{3}-S_{1}$. (f) Wear surface of $C_{3}$.

TABLE 3: UBM and MRM for the three specimens.

\begin{tabular}{lcccc}
\hline & & $\mathrm{C}_{1}$ & & $\mathrm{C}_{2}\left(\mathrm{C}_{3}\right)$ \\
& $\mathrm{UBM}$ & $\mathrm{MRM}(\%)$ & $\mathrm{UBM}$ & $\mathrm{MRM}(\%)$ \\
\hline $\mathrm{SE},\left(\mathrm{MJ} / \mathrm{m}^{3}\right)$ & 20 & 65 & 40 & 65 \\
$\mathrm{CC},(\%)$ & 20 & 45 & 1 & 30 \\
$a_{v},(g)$ & 1 & 80 & 300 & 80 \\
$\sigma_{\max },(\mathrm{MPa})$ & 100 & 85 & $1 / 1.8$ & 85 \\
$1 / l_{w},(\mathrm{~km})$ & $1 / 5.4$ & 85 & 90 \\
\hline
\end{tabular}

TABLE 4: PPM (nondimensional).

\begin{tabular}{lccccccccc}
\hline & $\mathrm{C}_{1}-\mathrm{S}_{1}$ & $\mathrm{C}_{1}-\mathrm{S}_{2}$ & $\mathrm{C}_{1}-\mathrm{S}_{3}$ & $\mathrm{C}_{2}-\mathrm{S}_{1}$ & $\mathrm{C}_{2}-\mathrm{S}_{2}$ & $\mathrm{C}_{2}-\mathrm{S}_{3}$ & $\mathrm{C}_{3}-\mathrm{S}_{1}$ & $\mathrm{C}_{3}-\mathrm{S}_{2}$ & $\mathrm{C}_{3}-\mathrm{S}_{3}$ \\
\hline $\mathrm{SE}$ & 5.75 & 3.20 & 1.32 & 1.51 & 5.66 & 7.92 & 2.65 & 4.72 & 8.62 \\
$\mathrm{CC}$ & 4.89 & 4.33 & 1.44 & 3.00 & 5.42 & 6.17 & 6.67 & 6.92 & 9.08 \\
$a_{v}$ & 7.00 & 7.63 & 8.50 & 6.75 & 7.75 & 5.88 & 7.75 & 8.50 \\
$\sigma_{\max }$ & 7.78 & 10.00 & 10.00 & 1.15 & 5.53 & 9.22 & 0.82 & 5.75 \\
$l_{w}$ & 2.96 & 4.38 & 9.70 & 5.68 & 1.72 & 9.55 & 5.28 & 1.06 & 9.13 \\
\hline
\end{tabular}

performance must be carefully considered and the above mentioned measures should only be used if necessary.

For evaluating the overall performance, the OPI functions are used to quantitatively estimate the performance levels of the cutters incorporating their expected best performances. Prior to the calculation of OPIs, it is necessary to define the importance levels of the criteria. Specifically, weighting factors of performance parameters can be 
TABLE 5: Profile analysis for the performance parameters across all the specimens (nondimensional data).

\begin{tabular}{lccccccccc}
\hline & \multicolumn{3}{c}{ Mean } & & & SD & & \multicolumn{2}{c}{ PPI } \\
& $\mathrm{C}_{1}$ & $\mathrm{C}_{2}$ & $\mathrm{C}_{3}$ & $\mathrm{C}_{1}$ & $\mathrm{C}_{2}$ & $\mathrm{C}_{3}$ & $\mathrm{C}_{1}$ & $\mathrm{C}_{2}$ & $\mathrm{C}_{3}$ \\
\hline $\mathrm{SE}$ & 3.43 & 5.03 & 5.33 & 2.22 & 3.25 & 3.03 & 2.42 & 3.11 \\
$\mathrm{CC}$ & 3.56 & 4.86 & 7.56 & 1.85 & 1.65 & 1.33 & 2.66 & 4.41 & 7.25 \\
$a_{v}$ & 7.71 & 6.79 & 7.67 & 0.75 & 0.94 & 0.88 & 7.66 & 6.71 & 7.60 \\
$\sigma_{\max }$ & 9.26 & 5.30 & 5.08 & 1.28 & 4.04 & 4.16 & 9.13 & 2.59 & 1.98 \\
$l_{w}$ & 5.68 & 5.65 & 5.26 & 3.56 & 3.92 & 4.19 & 4.48 & 3.48 \\
\hline
\end{tabular}

TABle 6: Profile analysis of the cutters under three specimens (nondimensional).

\begin{tabular}{cccccccccc}
\hline & \multicolumn{3}{c}{ Mean } & & \multicolumn{2}{c}{ SD } & \multicolumn{2}{c}{ CPI } & $\mathrm{C}_{1}$ \\
& $\mathrm{C}_{1}$ & $\mathrm{C}_{2}$ & $\mathrm{C}_{3}$ & $\mathrm{C}_{1}$ & $\mathrm{C}_{2}$ & $\mathrm{C}_{3}$ & $\mathrm{C}_{3}$ \\
\hline $\mathrm{S}_{1}$ & 5.68 & 3.62 & 4.63 & 1.88 & 2.50 & 2.86 & 5.06 & 2.28 \\
$\mathrm{~S}_{2}$ & 5.91 & 5.22 & 5.30 & 2.82 & 2.18 & 2.79 & 4.99 & 3.99 \\
$\mathrm{~S}_{3}$ & 6.19 & 7.75 & 8.61 & 4.43 & 1.69 & 1.08 & 2.83 & 7.44 & 3.11 \\
\hline
\end{tabular}

determined by their contributions to the overall TBM performance such as tunneling cost and advance rate; weighting factors of geological conditions are largely dependent on the corresponding proportions along the tunnel alignment (rock types). For illustration purpose, the OPIs of the three cutters under different sets of weighting factors (simply given by expert scoring method, see Table 7) are illustrated in Figures 4 and 5.

From these figures, it can be seen that the OPIs are determined by both the performances and the weighting factors. Undoubtedly, when high priority is put in $\sigma_{\max }$ and $\mathrm{S}_{1}$ (referred to as Set III-2), the highest OPI (close to 35) and lowest OPI (close to 10) can be found for $\mathrm{C}_{1}$ and $\mathrm{C}_{3}$, respectively (see Figure 4(c)). The huge difference between the two OPIs suggests that $C_{1}$ has a significant advantage over $C_{3}$ under Set III-2. By comparison, slight difference can be observed under Set III-4, which suggests both $\mathrm{C}_{1}$ and $\mathrm{C}_{1}\left(\mathrm{C}_{1}\right)$ can be used under given circumstances. It is also worth to note that the relative position of OPI data points in each figure almost remains the same no matter which set of weighting factors of performance (or specimens) is chosen. For example, in Figure 4, the highest OPI of $\mathrm{C}_{1}$ can always be found under the Set 2, followed by the OPIs under the Set 3, Set 1 and Set 4 . The similar rules can be observed in Figure 5.

When the tunneling ground only (or mainly) contains $\mathrm{S}_{3}$-like composition (e.g., Figure 5(d)), undesirable large SE and $\mathrm{CC}$ will put $\mathrm{C}_{1}$ at an obvious disadvantage and therefore a relatively low OPI is likely to be obtained in most cases regardless the small fluctuations in weighting factors. In other words, trends reflected in the OPIs support this notion that weighting factors can affect the value of OPIs to some extent; the proposed evaluation method has necessary tolerance of uncertainty in weighting factors. Despite all these, a more applicable strategy for the selection of weighting factors should be fully discussed in the future work.

Based on the above analyses, the performance of the cutters is systematically evaluated with respect to the
TABle 7: Different sets of weighting factors (\%).

\begin{tabular}{lccccccccc}
\hline & \multicolumn{3}{c}{ Performance parameters } & \multicolumn{5}{c}{ Specimens } \\
& $\mathrm{P}_{1}$ & $\mathrm{P}_{2}$ & $\mathrm{P}_{3}$ & $\mathrm{P}_{4}$ & $\mathrm{P}_{5}$ & & $\mathrm{~S}_{1}$ & $\mathrm{~S}_{2}$ & $\mathrm{~S}_{3}$ \\
\hline $\mathrm{I}^{\mathrm{a}}$ & 20 & 20 & 20 & 20 & 20 & $1^{\mathrm{a}}$ & 33 & 33 & 33 \\
$\mathrm{II}$ & 60 & 10 & 10 & 10 & 10 & 2 & 80 & 10 & 10 \\
$\mathrm{III}$ & 10 & 10 & 10 & 60 & 10 & 3 & 10 & 80 & 10 \\
$\mathrm{VI}$ & 10 & 10 & 10 & 10 & 60 & 4 & 10 & 10 & 80 \\
\hline
\end{tabular}

$\mathrm{I}^{\mathrm{a}}$ and $1^{\mathrm{a}}$ denote the first set of weighting factors of the performance parameters and specimens, respectively.

performance parameters which collectively describe the overall performance. In order to combine these parameters, the results obtained from experiments, FEA, and theoretical calculation are converted into nondimensional scores using a linear relationship based on the actual performance to its performance limit. The core of the above conversion is the proximity of the level at which the cutters will perform with respect to the expected best level and acceptable level of the performance described by two matrixes: UBM and MRM. They should be reasonably given by the designers based on their engineering experience; otherwise, the evaluation could be subjected to errors. However, the introduction of these two matrices is inevitable in a design assessment because the evaluation results would not be meaningful unless the performances are judged against the design criteria.

It is a common practice that detailed engineering analyses might be carried out by several engineers with different specialisms especially for large and complex systems like TBMs. The process proposed in this paper brings together the separate analyses and combines them into a manageable design review procedure, which means that the evaluation method has an intrinsic applicability to evaluate the suitability of a TBM cutterhead on a given project. Particularly, this design synthesis concept provides a framework for formulating the quantifiable portion of a system design on which advanced optimization techniques can be brought to 

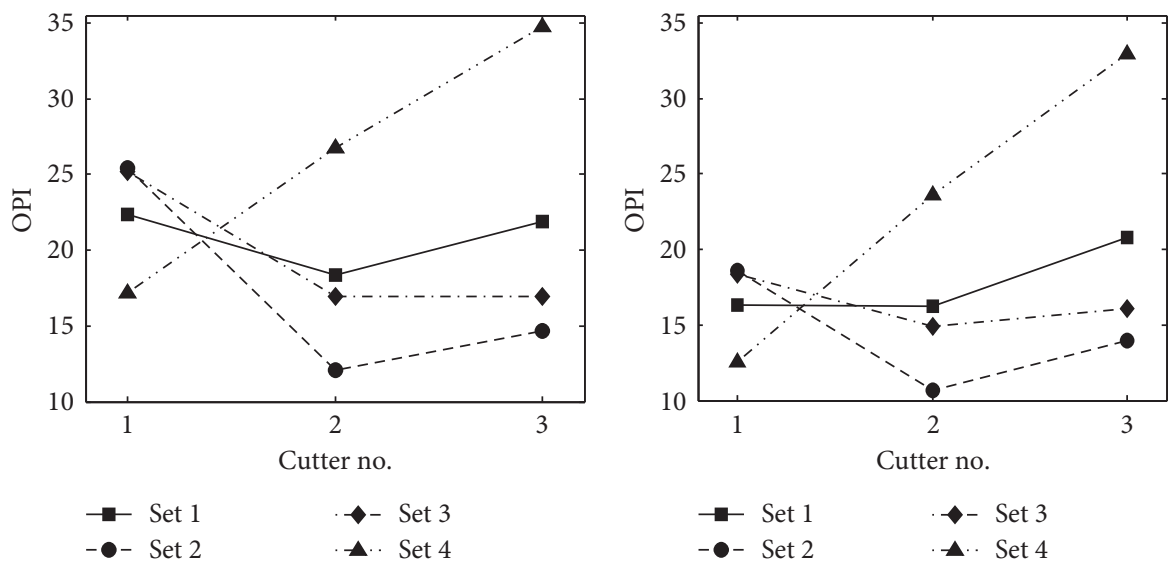

(a)

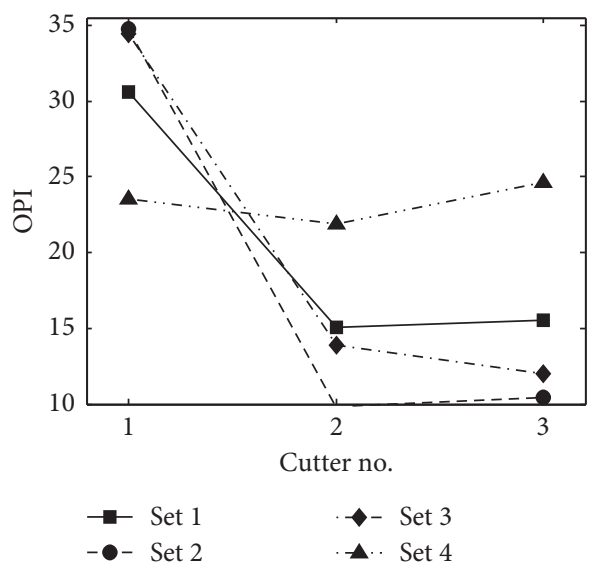

(c)

(b)

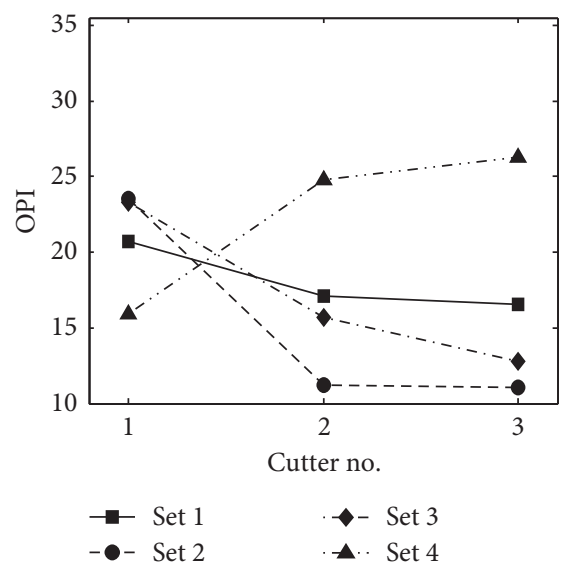

(d)

FIGURE 4: OPIs of the three cutters under different sets of weighting factors of performance parameters. (a) Set I. (b) Set II. (c) Set III. (d) Set VI.

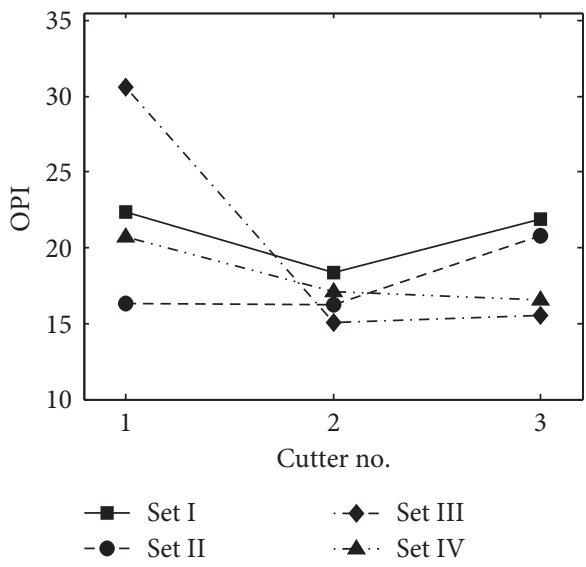

(a)

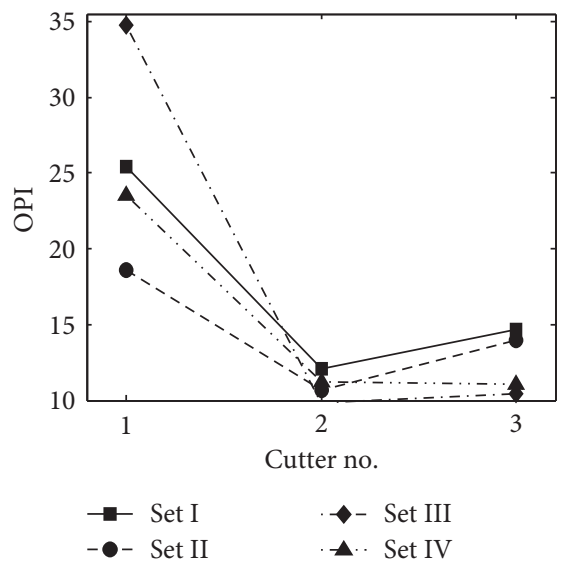

(b)

Figure 5: Continued. 


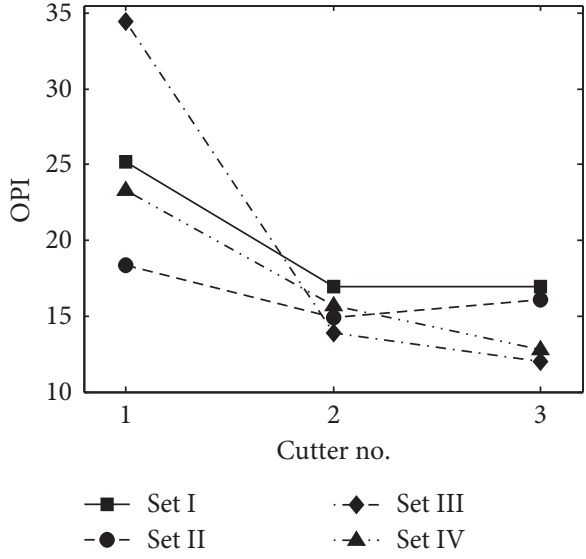

(c)

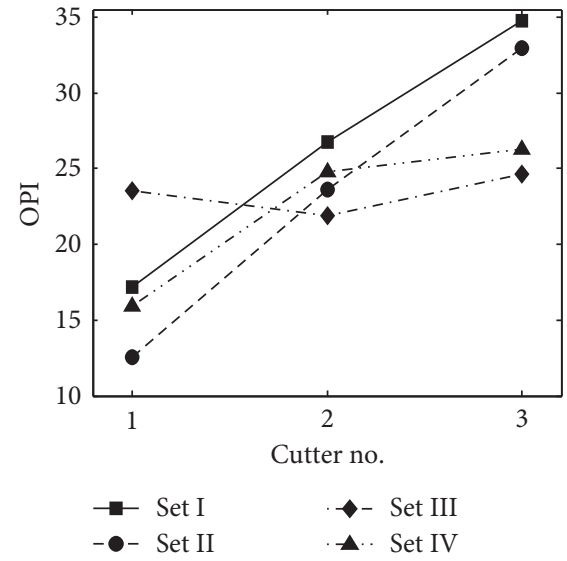

(d)

Figure 5: OPIs of the three cutters under different sets of weighting factors of geological conditions. (a) Set 1. (b) Set 2. (c) Set 3. (d) Set 4.

bear. It would be the future work that a computer-aid optimization program should be developed for TBM cutterheads.

\section{Conclusions}

A novel systematic method has been devised to evaluate the overall performance of TBM cutters with respect to different kinds of performances and geological conditions. This method enables the designers to make a quick selection of proper cutters prior to layout design of the cutterheads.

For a design review exercise, the method aims to identify the "weak spots" in the original design, which could help the designers to make a more targeted redesign for refurbishment.

The merits of the three experimental cutters are discussed by applying the proposed evaluation method. By using the method, a reasonable selection among the cutters could be made quantitatively for a mixed geological condition.

\section{Data Availability}

The data to support the findings of this study are available from the corresponding author upon request.

\section{Conflicts of Interest}

The authors declare that there are no conflicts of interest.

\section{Acknowledgments}

This project was supported by the National Natural Science Foundation of China (51704256, 11832016, and 51775471), Natural Science Foundation of Hunan Province, China (2020JJ4583 and 2017JJ3292), and Scientific Research Project of Hunan Education Department (19C1756), China. This project was also supported by the Changsha Zhuzhou Xiangtan Landmark Engineering Technology Project (2019XK2303 and 2020GK2014) and Xiangtan Science and Technology Project (ZD-ZD20191007).

\section{References}

[1] L. Lin, Y. Xia, Q. Mao, and Z. Xuhul, "Experimental study on wear behaviors of TBM disc cutter ring in hard rock conditions," Tribology Transactions, vol. 61, no. 8, pp. 1-41, 2018.

[2] X. Sun, C. Ren, J. Yuan, J. Du, J. Liu, and B. Guo, "The analysis of time-space effect of surrounding rock deformation of TBM tunnels in deep composite stratum with or without support," Advances in Civil Engineering, vol. 2020, Article ID 5494192, 21 pages, 2020.

[3] J. Liu, P. Cao, and D. Han, "Sequential indentation tests to investigate the influence of confining stress on rock breakage by tunnel boring machine cutter in a biaxial state," Rock Mechanics and Rock Engineering, vol. 49, no. 4, pp. 1-17, 2015.

[4] J. W. Cho, S. Jeon, H. Y. Jeong, and S. H. Chang, "Evaluation of cutting efficiency during TBM disc cutter excavation within a Korean granitic rock using linear-cutting-machine testing and photogrammetric measurement," Tunnelling and Underground Space Technology, vol. 35, pp. 37-54, 2013.

[5] G. Wang, T. Ren, and G. Zhu, "The influence of confining stresses on rock fragmentation, thrust force, and penetration energy in sandstone indentation tests using disc cutters," Advances in Civil Engineering, vol. 2021, Article ID 5541538, 13 pages, 2021.

[6] J. Liu, P. Cao, and D. Han, "The influence of confining stress on optimum spacing of TBM cutters for cutting granite," International Journal of Rock Mechanics and Mining Sciences, vol. 88, pp. 165-174, 2016.

[7] J. Liu and J. Jiang, "Use of laboratory indentation tests to study the surface crack propagation caused by various indenters," Engineering Fracture Mechanics, vol. 241, no. 4, Article ID 107421, 2020.

[8] J. Roby, T. Sandell, J. Kocab, and L. Lindbergh, "The current state of disc cutter design and development directions," in Proceedings of the 2008 NorthzAmerican Tunneling Conference, SME C, pp. 36-45, San Francisco, CA, USA, January 2008.

[9] R. Gertsch and L. Ozdemir, "Performance prediction of mechanical excavators from linear cutter tests on yucca mountain welded tuffs," International Atomic Energy Agency, Vienna, Austria, 24027608, 1992.

[10] W. Sun, J. Ling, J. Huo, L. Guo, X. Zhang, and L. Deng, "Dynamic characteristics study with multidegree-of-freedom 
coupling in TBM cutterhead system based on complex factors," Mathematical Problems in Engineering, vol. 2013, Article ID 635809, 17 pages, 2013.

[11] C. Frenzel, H. Käsling, and K. Thuro, "Factors influencing disc cutter wear," Geomechanik und Tunnelbau, vol. 1, no. 1, pp. 55-60, 2008.

[12] G. Wijk, "A model of tunnel boring machine performance," Geotechnical \& Geological Engineering, vol. 10, no. 1, pp. 19-40, 1992.

[13] J. S. Liu and T. J. Lu, "Multi-objective and multi-loading optimization of ultralightweight truss materials," International Journal of Solids and Structures, vol. 41, no. 3-4, pp. 619-635, 2004.

[14] Q. Tan, Z. J. Xu, Y. M. Xia, and K. Zhang, "Numerical simulation and experimental observation of rock cracks under action of spherical tooth hob cutter," Chinese Journal of Rock Mechanics and Engineering, vol. 29, pp. 163-169, 2010, in Chinese.

[15] J. Rostami, L. Ozdemir, A. Bruland, and F. Dahl, "Review of issues related to cerchar abrasivity testing and their implications on geotechnical investigations and cutter cost estimates," in Proceedings of the Rapid Excavation and Tunnelling Conference (RETC), Seattle, Washington, U.S.A., June 2005.

[16] A. Bruland, Hard Rock Tunnel boring, Norwegian University of Science and Technology, Trondheim, Norway, 1998. 